\title{
Discussion
}

\section{Future avenues for education and neuroenhancement}

\author{
Selma Dündar-Coecke \\ Centre for Educational Neuroscience \& Department of Psychology and Human Development, UCL Institute of Education, University College London \& QBA, UK
}

\section{A R T I C L E I N F O}

\section{Keywords}

Education

Neuroscience

Future

Learning

Neurointervention

\begin{abstract}
A B S T R A C T
Education, in epistemological terms, presents an arena in which the development of knowledge and its transmission frame fundamentally distinct assignments: in social contexts knowledge exchange is prioritised to equip individuals as knowers; in theoretical contexts, an understanding of knowing as a state of mind is the primary objective. Distinguishing between education and its institutionalised product -the school-, this paper reviews the notion that today's modern classroom settings limit the applicability of neuroscience research by focusing on equipping individuals as knowers. In contrast, educational research has become increasingly grounded in brain sciences, with future premises examining artificial intelligence technologies (AI) targeted at enhancing learning and memory based on an understanding of the nature of knowing. Taking into account this bifurcation between education and school, this paper examines how the paths of educational, neuroscience, and AI research cross beyond school-enabled learning. This is contemplated across three sections. The first section examines the historical basis of the bifurcation between education and schooling. The second reviews the potential impacts of current neuroscience knowledge on educational implementations. The third discusses how and why neuroscience and AI technologies could be pertinent to educational discourse in the future.
\end{abstract}

\section{Introduction}

Neuroscience is a field that examines the structure and function of the nervous system. Artificial intelligence (AI) is a machine architecture that is analogous to the networks of neurons that comprise the brain, whereas education encompasses learning, teaching, social, and organizational aspects of educational outcomes. Opinions about the strength of the link between these fields diverge largely, particularly for education and neuroscience. At the negative end, some reject the possibility of applying neuroscience knowledge directly to education; their criticisms underline the inapplicability of neuroscience research in classroom settings, and pinpoint the theoretical, practical, and methodological differences between the two areas (e.g., Bishop, 2014; Bowers, 2016; Bruer, 1997, 2013). In contrast, more positivist arguments highlight the value of the interoperability between the fields, pointing to the benefit of providing a platform to improve the quality of the dialog between psychologists, educators, and teachers (Goswami, 2004); the possibility that this dialog could reduce the prevalence of neuromyths among educationalists (Howard-Jones, 2014); and the power of this link in improving learning strategies through better understanding of cognition and brain function (Ansari et al., 2017; Dubinsky et al., 2019). The emerging fields 'educational neuroscience' and similarly 'Mind Brain Education Society' hold the view that there is actually no single bridge between education and neuroscience, but instead, the fields interact via two bi-directional routes (Thomas \& Ansari, 2020). One route relates psychology to neuroscience indirectly, whereby neuroscience evidence is used to advance theories of learning and thus indirectly affects instruction. The second route links neuroscience and education directly, by virtue of the fact that the brain is a biological organ, subject to metabolic processes, such as nutrition, fitness, or pollution, revealing non-psychological factors impacting on educational outcomes (see also Bell \& Darlington, 2020; Fisher et al., 2010; Schwartz, 2015; Thomas et al., 2019). In a broad sense, this multidisciplinary approach can guide an understanding of the characteristics of the learning brain, helping to diminish the mismatch between how we teach and how the brain learns (Rodriguez \& Fitzpatrick, 2014).

However, research in both lines of thought seems to omit the theory/ practice divide and focuses primarily on the link between cerebral activity and school implementations. The present paper underlines the theoretical and practical differences between schooling (the institution of instruction) and education (research and theories of learning, knowing and instruction) in the context of knowledge acquisition, meanings, and epistemic status. At its core, the target of education is the enlightenment -the ability of free thinking-as a natural propensity or capacity of self. In Kantian terms, this destination could only be reached through education, therefore what lies behind the theory of education are the

E-mail address: selma.coecke@gmail.com. 
cumulative efforts targeting the enhancement of human nature. This distinction is crucial because the notion of education cannot be reduced to mere instruction or classroom teaching, which at the very least lacks consideration of various introspective aspects, ranging from personality development to mindfulness or other environmental factors. Initially, Kant's essays pioneered the idea that learning and instruction are dissimilar activities; the latter prioritizes the forms of knowledge transfer within a series of arrangements as commonly practiced in schools. The term education instead gravitates around sustainable development, and is concerned with improving the goodness in human beings (Kant, 1900), supporting freethinking and natural development (Rousseau, 1763/1979), individual development resulting in societal contribution and social consciousness (Dewey, 1916).

Acknowledging this divergence, the present paper contains three subsections as illustrated in Table 1 . The first section examines the historical basis of this bifurcation to lay the foundations for the exploration of why neuroscience knowledge is relevant to education beyond school-enabled teaching/learning. The second section argues that potential impacts of neuroscience research on modern classroom implementations are usually indirect due to the limitations stemming from class level teaching itself. This section acknowledges why some people see connections between education and neuroscience, but others do not. The third section outlines a futuristic perspective and renders the ways in which AI and neuroscience knowledge is pertinent to education. This view regards the universal characteristics of knowledge as nonterritorial, produced through fluid interactions across fields.

\section{Acknowledging the disjunction between education and schooling: a historical review}

For hundreds of thousands of years children have been educated by elders towards a target, or by themselves through self-directed exploration and play (Montessori, 1912/1988; Tomasello, 1999). The hunter-gatherer lifestyle was skill intensive, whilst agriculture was labour focused. In agrarian communities, children were typically raised in extended families, and the majority of them worked in the fields, or looked after younger siblings, or helped with the household chores. In the early agricultural civilisations, only a very small number of elite children had the opportunity for formal education until industrialism brought about a paradigm shift that gradually changed the needs and indeed the definition of the notion of skill. Children were moved from the fields to the factories and involved in repetitive but specialised labour-intensive work. Education was understood within either religious, economic, or social contexts. Even in developed countries modern education has only come to be recognised very recently - with the rise of the bourgeoisie (in France, and America) educational rights were established as a public function (Bourdiou \& Passeron, 1970/1990; Ramirez \& Boli, 1987).

The necessity for a secular pedagogy was explicitly emphasized by $\mathrm{J}$. J. Rousseau. In his book Emile, or on education he (1763/1979)

Table 1

Overview of the sections.

\begin{tabular}{|c|c|c|}
\hline $\begin{array}{l}\text { 1. Acknowledging the } \\
\text { disjunction between } \\
\text { education and } \\
\text { schooling }\end{array}$ & $\begin{array}{l}\text { 2. Today: diagnosis of } \\
\text { the brain mechanisms } \\
\text { mediating learning }\end{array}$ & $\begin{array}{l}\text { 3. Future prospects: } \\
\text { neuroenhancement beyond } \\
\text { school-enabled learning }\end{array}$ \\
\hline $\begin{array}{l}\text { From pre-industrial } \\
\text { to post-modern era: } \\
\text { education vs. school } \\
\text { - Future scenarios } \\
\text { o Reschooling } \\
\text { o Deschooling } \\
\text { o Extending the } \\
\text { market model } \\
\text { o School as a place of } \\
\text { leisure }\end{array}$ & $\begin{array}{l}\text { - Dichotomy: positive } \\
\text { vs. negative views on } \\
\text { bridging education, } \\
\text { neuroscience, and AI } \\
\text { - Directions for the } \\
\text { ramification of } \\
\text { neuroscience research } \\
\text { o Diagnostic tests and } \\
\text { procedures trialling } \\
\text { interventions }\end{array}$ & $\begin{array}{l}\text { The range of neuro- } \\
\text { intervention technologies. } \\
\text { - Adding one more scenario: } \\
\text { coupling humans with } \\
\text { advanced machines/ } \\
\text { laboratory products. } \\
\text { o Neuroenhancement } \\
\text { technologies: from 'need' to } \\
\text { 'want'. }\end{array}$ \\
\hline
\end{tabular}

highlighted for the first time the notion of childhood and its specific education, as opposed to the medieval belief in children as little adults. The world-wide institutionalisation of these rights, coinciding with the emergence of public schools, is therefore European in origin; its characteristics were shaped by socioeconomic factors, later leading to age graded mass schooling in Europe and America. The variety of children's situations increased during the age of industrialisation. The agricultural patterns were largely unchanged in rural areas, in particular in nondeveloped/developing countries; most opportunities, even basic schooling, remained inaccessible for children from low socioeconomic status homes, even towards the end of the 20th century.

Until recently, the tripartite vertical structure of school systems in Europe was based on the Trinity Psychology of Talents (Trinitätspsychologie der Begabungen). Following this structure, the forms of abilities were defined as (1) theoretical, (2) practical, and (3) the mixture of theoretical and practical. The tripartite structure put social Darwinism into practice and blended the notions of talent and social classes in the heart of education. Until the present-day school reforms, this view prevailed. Schools functioned to maintain class-talent relationships, where top layers were allocated for individuals who show theoretical forms of talent and lower layers represented the practical, with the middle layers dominated by a mixture of the two (Aytaç, 1971; Wollmann, 2008). This view became untenable with the effects of post 2nd World War reforms, culminating in an egalitarian approach that defended the educational rights of talented children from lower strata.

Towards the 1960s, debates around taking environmental factors into consideration for educational achievement strengthened, and the concept of innate intelligence was attacked. During this period, the human capital approach rose, viewing workers as a form of capital with a set of marketable skills, and collectively as an important indicator of economic growth. Most models measuring the productivity of human capital used the rate of average schooling years as a proxy (Jones \& Schneider, 2006). It also became common to use IQ data for comparisons, judging achievement scores for math, science and reading as predictors of workers' productivity and, by extension, economic growth (Jensen, 1998). Around the 1970's, the tendency to simplify the function of education in this context caused critical pedagogists like I. Illich to define education as secular religion. Towards the end of modernism, the developments in psychology (psychologie différentielle $=$ differential pedagogy) influenced educational practices and reduced the effect of the trinity skills approach, with the consequence that more care for children with different ability levels was taken. Children's adaptation, namely their individual characteristics even within the same classroom, became an important educational motto.

In modern societies, the aim of education revolved around the tenet of cognitively enhancing students. Family planning policies developed, and the number of years spent in school was extended, with longer periods of training particularly for white collar occupations (Herrnstein \& Murray, 1994; Roser \& Ortiz-Ospina, 2019). Many governments attempted to expand schooling to provide more opportunities to children from low socioeconomic homes. Ironically, given this boost towards egalitarianism, schools came to work as scanning tools to differentiate more intelligent children from less intelligent ones. The consequences of this new function -schooling as a scanning tool-was described as IQ'ism by Marxists; and as credentialism by a group of sociologists (see Macionis, 2003; also Collins' The Credential Society). A new approach gained momentum, positing that intelligence could be measured with standardised IQ tests, and these measurements can serve as proxies for educational attainments, and therefore social mobility. The modernist school became an immense bureaucratic assessment industry, providing the basis for cognitive capitalism, with massive economic and political influence in society (see Bourdieu's 1993 dedicated chapter on the racism of intelligence; Foucault, 1982; Rindermann, 2018).

Postmodernism views education as knowledge intensive, allowing for an aimless anarchism and chaos via personalized implementations (Heidegger, 1968, 1993). It signifies not the end of the modernist era, 
but instead an extension of modernism, evolving through global events and new technologies (Lyotard, 1984). Cognitive liberty stands as a fundamental right, prompting individuals to acknowledge the value of their own cognitive states, values, beliefs -and encouraging them to be sceptical about the status and the function of schooling (Derrida, 1992; Foucault, 1982, 1995). Such scepticism sees schools as part of the hegemony, and as such they need to be dethroned. The function of schooling is driven by a knowledge-based economy, and students' results are primarily analysed at a social level, rather than for the benefit of the individual. Criticisms which reflect upon the individuals' point of view, on the other hand, question whether every school year is a worthwhile investment in the acquisition of skills and knowledge (Bourdiou \& Passeron, 1970/1990).

Postmodern discussions are quite diverse, but are primarily concerned with the socioeconomic aspects of education revolving around four possible scenarios acting upon the future of education:

- The first is framed under the heading of reschooling which refers to maintaining the school as a core social centre in which children learn through social interactions. The claim is that modernist schools are incapable of resolving today's problems or preparing learners for tomorrow's requirements. The notion of knowledge is a dead issue in education as the new concern now is accessing more information (Loh, 2001). Schools should remain as key institutions for the public good, but their social/community role needs to be prioritised. In this framework, students are allowed to work at their own pace to master their abilities (OECD, 2001).

- Another scenario is framed under the heading of deschooling, which draws upon critiques stating that schools are designed to address the needs of the industrial age, imitating the industrial factory model in which a certain number of children are exposed to a standardised curriculum and then ranked through a grading system (Illich, 1971). In this scenario the proposal is to replace outdated institutional schooling with learning networks and turn education into a non-institutional large-scale infrastructure of contemporary network society. The deschooling vision is modelled around the internet and technology, favouring virtual community-based learning networks rather than modern classrooms which have accelerated in line with Taylorist (behaviourist) terms for decades.

- The third scenario proposes extending the market model to allow for private funding opportunities and therefore encouraging entrepreneurialism in education. This model places more emphasis on the knowledge-based economy than other social and cultural aspects, with the assumption that productivity and economic growth will remain a central function of education. However, it is posited that the nature of the reciprocal relationship between education and productivity will evolve with the aid of knowledge distribution and information processing technologies (Kenway et al., 2004; OECD, 1996, 2000a; Webster, 2002).

- Another scenario proposes moving back to the original etymology: school as a place of leisure. The shift towards leisure, community activities and more informal engagements with individualised programmes is emphasized. Widespread dissatisfaction with the bureaucratic nature of schools and lack of public spaces devoted to play are the main concerns. Schools, as key social institutions, should foster non-cognitive aspects of social beings, such as friendships, play, and fundamental values that encourage individuals to volunteer and engage in political and social life (OECD, 2001). The whole idea is about edutainment, which is built on the premise that learning can be fun, and where students come to school to achieve a higher level of mastery through experiment and play (Gee, 2003).

Not all nations or school systems experience postmodernism in the same way, but in western cultures, schools are increasingly marked by a tendency to adapt to one/some of these scenarios. For instance, learners are less likely to be exposed to the same amount of information as the rest of their classmates; or teachers are no longer the sole source of knowledge for new generation learners. Teaching/learning practices are more individualised and based on small groups. Educational content is incidental, which means that learning can occur whilst carrying out any kind of activity, even outside the school, not restricted to curriculum content or memory skills. The varieties in learning resources are empowered by intelligent technologies, particularly with the aid of distance learning opportunities or Artificial Intelligence (AI) systems, premising that in such societies the next generation of learners will no longer be dependent on classroom teaching as previous generations were (Moghaddam et al., 2019; OECD, 2012).

Considering the ways in which this educational machinery operates, the next section reviews the notion that strengthening the connection between neuroscience and today's educational institutions is a challenging task. Bringing neuroscience and AI research to the classroom may particularly confuse some educationalists and also neuroscientists, as today's schools are still wearing their modernist uniforms, with centralised curricula, allowing for mastery over subject-matter, spatially dependent on institutional buildings, and where educators stand as legitimate authorities.

\section{Today: diagnosis of the brain mechanisms mediating learning}

Research has produced significant advancements in neuroscience and its subfields, ranging from cellular to molecular, and revolutionised the ways in which we observe and understand the molecular mechanisms guiding the neural system, its maturation, disorders, and impacts on behaviour (Squire et al., 2013). Positive arguments acknowledged the ramifications of the advancements in neuroscience for education, with broad implementations of new methodologies that build upon different levels of analysis and powerful tools, aiming to contribute to teaching and learning practices (Blakemore \& Frith, 2005; Stern, 2005). More cautious opinions about the potential of this interaction argue that a direct impact of educational neuroscience on classroom implementations is an unrealistic expectation (Willingham, 2009). The difficulty of reflecting neuroscience research into the classroom seems to stem from a number of issues, such as the limitations of neuroscience knowledge itself (Bruer, 1997), language barriers between the two fields, poor communication between scientific researchers and educational practitioners (Pickering \& Howard-Jones, 2007), objective boundaries (Beauchamp \& Beauchamp, 2013; Bishop, 2014), scientific and pragmatic difficulties in translating neuroscience research results into direct classroom applications (Szücs \& Goswami, 2007; Varma et al., 2008), and other moral and political issues (Davis, 2004). A cautious approach is also necessary when evaluating the quality of neuroscience evidence, as mental processes emerge from the interactions of multiple brain regions, and measuring their activities brings several challenges (Poldrack, 2008).

Although progress has been challenged by methodological constraints and a lack of available tools, educational research has benefited substantially from the use of neuroimaging technologies providing more accurate evidence for the identification of neurocognitive processes. Access to such precise evidence occurs through the examination of brain structure and functions. The information flow in the brain occurs via chemical and electrical signals, and neural activities can be detected by both invasive (e.g., single-cell recording) and non-invasive methods (e. g., electroencephalogram - EEG, magnetic resonance imaging - MRI). For instance, structural properties, such as the skull, grey matter and white matter can be visualized by MRI, whereas brain activity can be measured using functional MRI (fMRI), which provides indirect measures for regional activity via the assessment of the cerebral blood flow and oxygenation while the participant performs a cognitive task (Dumontheil \& Mareschal, 2020; Ward, 2010). Both MRI and fMRI can provide good spatial resolutions and help to identify the neural networks that associate with the cognitive task. Another commonly used non-invasive neuroimaging technique in educational research is EEG. 
This method provides good temporal resolutions in the order of milliseconds and helps to map the temporal sequence of a cognitive process.

The spatial and temporal resolutions enabled by these tools are crucial in exploring the unknown nature of typical and atypical neural development with more precision (Dick et al., 2013; Johnson \& de Haan, 2015). These technologies are available to researchers working in the fields of learning, instruction, and disorders, with well-established research programmes focusing specifically on core school subject areas, such as reading or mathematics, which are fundamental to children's survival in school systems. Studies of interest focusing on these areas are outlined briefly below to show how these technologies can help educationalists.

In the field of numeracy, Smedt (2014) introduces the ways in which neuroimaging methods/tools advance the understanding of mathematics learning. One strand of research aims to reveal neurocognitive correlates which are crucial for deciphering the sources of individual differences in arithmetical development. This research program evidences the importance of the intraparietal sulci (IPS) (Smedt, 2020), superior temporal gyrus (STG) and inferior frontal gyrus (IFG) activations in the processing of numerical magnitudes and solving simple arithmetic problems (Artemenko et al., 2019). Children with persistent difficulties in processing mathematical competences show increased activity in the IPS, but less activation in the STG and IFG, unlike their more arithmetically fluent peers (see also Ansari, 2008; Dehaene et al., 2003; Artemenko et al., 2019). The frontoparietal connectivity has also been found to be relevant to math performance in children (Emerson \& Cantlon, 2012). Working with professional mathematicians, Amalric and Dehaene (2018) reported activations of a bilateral network involving prefrontal, parietal, and temporal areas during advanced mathematical tasks. These activations were independent of well-known language-related areas in the left hemisphere, indicating the possibility of a major separation between the two brain networks responsible for mathematical and non-mathematical semantics. Further research programs focus on diagnostic instruments, aiming to capture the earliest indications of atypical patterns in mathematical development (e.g., Nosworthy et al., 2013), which in turn provides theoretical grounds for specific interventions, such as how to manipulate a given neurocognitive factor to reveal what factors are causal or not. One of the major contributions of these research programmes to our understanding is the proposition that there seem to be more specific variables playing a role in individual differences unique to mathematics learning beyond well-known contributors such as sensory dysfunction, intelligence, or socioeconomic status (see Smedt, 2020, for a review).

Much has been learned from neurological diagnostic tests that allow experts to view the structure of the brain, changes in brain activity and the amount of indicative brain chemicals commonly associated with reading and disorders: spatial resolutions were recorded using fRMI and studies commonly showed a large-scale network of left frontal, temporoparietal, and occipitotemporal regions engaged in reading (Houdé et al., 2010; Turkeltaub et al., 2003). Studies using EEG/ERP technologies have advanced the knowledge of the temporal course of reading. Longitudinal studies using these technologies help to predict reading difficulties at early ages. For instance, Molfese (2000) recorded 186 infants' brain activity within 36 hours of birth in which infants were exposed to a few passive speech stimuli (such as bi, di) during sleep. A follow up at 8 years of age of the same children compared their ERP components (N1, P2, N2), and found that the ERPs recorded at birth could distinguish $76.5 \%$ of children with dyslexia, $100 \%$ of poor readers, and $79 \%$ of control children at age 8. Lyytinen et al. (2005) recorded ERPs of 100 children with familial risk for dyslexia and 100 children without. ERP activities in the right hemisphere in children with risk for dyslexia correlated with poorer language skills at the age of 2.5; poorer verbal memory and reduced phonological skills at the age of 5; and slower lexical access and letter reading ability at the age of 6.5 (see Tong $\&$ McBridge, 2020, for a review). These studies exemplified that the patterns for poor reading can be detected early on by investigating the brain activations in the areas that are typically associated with reading. This could potentially encourage parents to approach much earlier intervention options, long before their children start primary school or fail to learn how to read, an issue most currently experienced around the age of 8.

Studies also showed that a child needs to structure a phonological system of spoken language prior to reading development. This structure helps children to build knowledge about phonological hierarchies -from syllables to onsets and rhymes-so that then any larger units (syllables) can be divided into its smaller units (rhymes). In fact, efficient readers show advanced phoneme and orthographic awareness, whereas children with reading difficulties perform poorly at all levels -syllable, rhyme or phoneme. The neuroscience research revealed that reading is not just about the ability to deal with visually crowded letters; nor is it independent of auditory speech processing. The term 'amplitude modulation' -accurate perception of variations in loudness/signal intensity-is used to explain the role of phonological awareness: accurate neural encoding of the statistical patterns of auditory information are nested in the amplitude modulation, and this corresponds to individuals' ability to manipulate phonological units in words (see Goswami, 2020, for a review; Goswami \& Szüics, 2011).

The above examples foreground the value of neural evidence for education. Overall, the benefits of neuroscience knowledge for education seem to be threefold:

- The use of neuroscience technologies can help researchers to unpack unknown aspects of behaviour, just as shown by Goswami's research program which identified a new sensory/neural basis for reading difficulties and development. When measured only by behavioural methods, individuals' performance can be driven by a number of different factors. To give an example, Laffere et al. (2021) found that while children with ADHD displayed worse performance on an auditory (temporally-selective) attention task, this did not reflect difficulties with attention, since they showed a robust effect of attention in the EEG signal; instead, their poor performance reflected difficulty encoding the stimuli into working memory. These examples support the notion that (i) cognitive processes cannot be consciously captured solely through behavioural methods, and (ii) behavioural responses themselves are insufficiently specific to rule out other possibilities.

- Neuroscience evidence has already informed educationalists that although learning potentially occurs at all ages, some activities, such as second language learning (e.g., Phelps \& Filippi, 2020) or musical instrument training (e.g., Schellenberg, 2020) may require more effort at older ages, suggesting that there may be more sensitive periods, whereby the brain primarily requires low-level sensory-motor inputs rather than high level concepts. This is highly crucial for educationalists when they make decisions about the quantity ratio of conceptual, perceptual and sensory-motor activities in educational settings.

- It is yet more intriguing to see how a particular cognitive function can be closely related to the same neural network(s) [(e.g., the link between prefrontal cortex and executive function; the association between auditory processing of lexical information and inferior prefrontal cortex (Kwok et al., 2017)], opening up possible opportunities for evidence-based interventions to help students enhance their cognitive capacities.

Despite the appeal of the evidence highlighting the link between brain structure, intellectual behaviour and the advantage of remedial programmes, the impacts of neuroscience knowledge on school implementations are limited. Attempts to make use of neuroscience knowledge in classroom-enabled teaching are impeded by the modernist nature of school machinery itself. For hundreds of years, schools have prioritised the social and economic aspects of education upfront, classifying and grading children/young people based on factors other than 
just their cognitive functions. Today's classrooms still reflect the industrialist factory model of education, where a crowd of children is grouped into classes according to non-pedagogical criteria, such as the area in which they live or strict age-based arrangements. Moreover, today's schools are socially, politically and culturally diverse institutions, where pedagogical concerns are seemingly prominent. A proposal suggesting the benefits of neuroscience research in school implementations needs to satisfy these institutional nuances. The view advocating for neuroscience evidence as directly relevant to classroom activities needs to contend with the fact that a child is only one member of the classroom, contributing to the dynamics of this community, where instructional tasks are primary; and then a part of the whole school, in relation to perpetuating the existing power relations. In this set-up, teachers do not have sufficient time to focus on individuals' needs.

On the other hand, acknowledging these limitations does not negate the fact that current educational theories have been augmented with neuroimaging, computational, and behavioural research methods, showing that reconciling data from separate levels of analyses can reveal important aspects of cognitive processes (Thomas et al., 2019). In fact, embracing multi-model research paradigms seems to be appropriate and timely. Although current neuroscience knowledge does not allow us to tell, for instance, whether an individual is good at math or reading, or how their neurobiology can be boosted, it does expand our understanding of why the neurobiological mechanisms corresponding to variations in behaviour cannot be interpreted precisely, and how continuous interplay between multiple factors, such as genetic and environmental, drive individual differences (The Royal Society, 2011, for a review), presenting a departure from a sole dependency on behavioural assessment methods in education.

The difference between the theoretical and applied research is also applied here. The latter is gaining momentum in education and is a viable tool for new emerging fields, such as educational neuroscience, which prioritizes the production of valid, applicable and useful knowledge for theorists and practitioners in this junction. In fact, a growing number of graduate and postgraduate courses (e.g., in Harvard and London universities) are aimed at translating neuroscience knowledge to education. Another new emerging strand -AI-enhanced human brain research-has also begun to accelerate, with the ability to emulate the brain, current models and tools processing complex data sets extracted from the images provide better precision. Furthermore, AI and machine learning algorithms seem to model and decode mental processes more reliably, hence enabling more precise interventions in the brain mechanisms mediating learning, emotions, and decisions (see e.g., Chen et al., 2020; Salvador et al., 2017; Yuste et al., 2017).

Despite this, there are counterarguments, with most criticisms of the applicability of neuroscience falling under the scope of schooling -whether or not classrooms are approachable/open to neuroscience evidence- rather than educational discourses. Current mainstream research in educational neuroscience has focused on potential routes to enhance individual learning and performance in or out of schools, and future developments are likely to emphasize this increasingly. The next section reviews how the notion of education rests on its epistemological commitments, inquiring into the origin, nature, methods and limits of human knowledge, recognised less by its formal institutions. Taking into account these epistemic commitments and recent research trends, the next section discusses how the brain sciences have been increasingly witnessing the integration of three major fields: cognition, education, and AI technologies, with competition between them decreasing.

\section{Future prospects: neural aspects of education beyond school- enabled learning}

As advances in neuroscience have led to further insights into learning and disorders, the possibility of using more advanced technologies to promote cognitive function have received more attention (see Moore, 2008, for a review). The range of neuro-intervention strategies involve an array of technologies which can provide a glimpse at insights for future directions. These involve, for instance, brain stimulation methods, pharmaceuticals, and brain-implants, mostly pertaining to altering the biochemistry and function of the brain, with potential impacts on the future of human learning as discussed below. However, it should not be taken for granted that AI or neuroscience offers a range of alternative technologies that are immediately relevant to education. The point here instead is to highlight that the range of neuroscience and AI research has deepened and widened, with recent applications encompassing the components of human learning that fall under the scope of education. Although this knowledge may not seem useful for educationalists in the near future, it is fundamental for discerning the neural mechanisms mediating human educability.

\subsection{Non-invasive stimulation technologies}

A group of non-invasive stimulation technologies have been widely used to temporally enhance cognitive abilities (Bartrés-Faz \& Vidal-Piñeiro, 2016; Walsh \& Pascual-Leone, 2003). One method is transcranial magnetic stimulation (TMS), which is where an electromagnetic coil that uses rapidly changing magnetic fields is placed on the scalp to induce action potentials in targeted brain regions. Single-pulse TMS is commonly used to explore brain functioning, while repetitive TMS (rTMS) is used to stimulate brain regions. Research reports long lasting improvements in perception, learning, and memory performance following TMS (rTMS) after the stimulation period (Grafman \& Wassermann, 1998), such as months-worth of enhancement in the ability to solve arithmetic problems (George \& Belmaker, 2000; Luculano \& Cohen Kadosh, 2013; Snowball et al., 2013), motor memory formation, and learning (Reis et al., 2008). A modified form of rTMS known as theta-burst stimulation (TBS) is also gaining popularity as a tool to increase working memory performance in healthy individuals, with recent studies reporting modulatory effects on cortical activity beyond the stimulation period (see e.g., Demeter et al., 2016; Tambini et al., 2018).

Similarly, transcranial direct current stimulation (tDCS) passes weak electrical currents to the brain via placement of electrodes attached to the scalp. Most cognitive tDCS studies have reported significant effects of tDCS on multiple networks in clinical and non-clinical participants (Clark et al., 2012; Flöel, 2014). It has been shown that tDCS can modulate executive and cognitive function of healthy participants (Miniussi et al., 2013); have long lasting and transferable effects on working memory when training is combined with the tDCS (Ruf et al., 2017); and increase sustained attention and target detection performance of healthy participants (Nelson et al., 2014; see also Coffman et al., 2014, for a review of studies reporting positive tDCS effects on healthy participants' attention, learning, and memory processes).

Transcranial random noise stimulation (tRNS) is another noninvasive electromagnetic stimulation method used to modulate cortical plasticity that uses random electrical oscillation spectrum over the cortex (Terney et al., 2008). tRNS effects are more pronounced in mitigating increased difficulty in arithmetic problem solving and learning (Popescu et al., 2016). Growing evidence suggests that it enables steeper learning in numerical tasks and the effects are more prominent than with cognitive training alone. In Cappelletti et al.'s (2013) study tRNS was combined with effective cognitive training and led to greater and longer lasting improvement in numerosity discrimination. A similar design (by Looi et al., 2017) involved children with learning disabilities and was found to be highly influential, enabling children to transfer their cognitive training outcomes to non-trained materials.

Although these technologies are quite recent, the subtle changes in neural activity they evoke generally seem to be well accepted as an option for enhancing neurocognitive function, with relative safety and low cost (Clark \& Parasuraman; Weiler et al., 2019). Given the numerous physical and biological factors influencing the neurointervention responses, the effects induced by these technologies may 
differ between studies (see e.g., Silvanto et al., 2018; Yeh \& Rose, 2019).

\subsection{Pharmacological enhancement}

Pharmacological enhancements with highly effective drugs have targeted neurochemical interventions, altering the molecular events underlying cognitive functions, such as memory and executive function (Farah et al., 2004). Most cognitive enhancers fall under two general classifications of action: direct mediators, such as glutamatergic agents, which impact on the mechanisms involved in synaptic plasticity; and modulators, such as adrenergic agents, which are capable of modifying diffuse networks of neurons in an indirect manner (Heinrichs, 2007). Much of the recent interest in both types of cognitive enhancers is fuelled by the pharmaceutical industry's experimentation with dementia, attention deficit and hyperactivity disorder (TheAcademy of Medical Sciences, 2007); but more recently, the kinds of drugs that have been experimented with to treat these conditions are increasingly being used by healthy individuals for the purposes of cognitive enhancement; as so-called smart drugs (Greely et al., 2008; Morein-Zamir \& Sahakian, 2011). Methylphenidate, amphetamine, piracetam, or modafinil are considered part of this group, and demand for these kinds of nootropics seems to be increasing. A sample of 1035 Franke et al. (2011), for instance, reported a $1.55 \%$ increase in the non-medical use of pharmaceutical cognitive enhancers in school pupils in Germany. Liakoni et al. (2015) also reported a prevalence in the use of cognitive enhancers among Swiss school students. Among students, usage of these enhancers seems to significantly increase during stressful times, particularly over the examination periods (Moore et al., 2014). Dietz et al. (2016) reported that the use of neuroenhancers is becoming common among economists, with e.g., the lifetime prevalence for the use of any enhancer hitting $88 \%$; sometimes they are used for enhancing mood, or for dealing with deadline pressures, or stress.

Although there are ongoing attempts to improve the chemical structures of existing medications by either enhancing their efficacy or reducing their side effects, this is an enormous market and the potential implications of drugs on education is unclear. Studies with animals and human species provide encouraging results with regards to optimising the molecular basis of memory -in the context of encoding, expression, and consolidation (Goff et al., 2001; Lynch, 2002; Lynch \& Gall, 2006). Furthermore, positive impacts with reduced side effects of an element-binding protein called CREB have been reported on long-term memory in mice (Josselyn et al., 2001) and in humans (see Barco et al., 2003; Kim et al., 2013, for a review). A recent meta-analysis study (Maraccini et al., 2016) found that in healthy adults the use of prescription stimulants has positive benefits on inhibitory control, working memory, and particularly on processing speed accuracy, with an overall mean effect size of $g=0.282$. However, the far-reaching ethical implications and regulatory issues surrounding the widespread use of these enhancers and their illegal use are still hot debates (see also Bostrom \& Sandberg, 2009; Maher, 2008; Partridge et al., 2011).

\subsection{Invasive technologies}

Another strand of research has focused on transitioning neuroscience knowledge into neurotechnology via advanced neural devices with impowered resolution and precision for neural interfaces, which enable a two-way channel of communication - from device to neurons, and vice versa (Donogue, 2002). Neural interface systems aim to connect the nervous system to a software, creating novel treatment avenues for some disorders [see TheRoyal Society, 2012, for a review). These technologies involve in-brain implants that directly stimulate particular regions to enhance the user's physical and cognitive capabilities (e.g., neuroprosthetic sensors, brain-computer interfaces -BCIs-enable humans to control external devices with neural signals). BCIs have been used to restore mobility and independence and more recently to repair human cognitive functions. Due to their invasiveness, costs and other ethical issues, implants are typically used for the treatment of medical conditions, ranging from epilepsy to depression. However, contemporary research trends are diverse, like the US Defense Advanced Research Project Agency's (DARPA, 2016a, b) current project called the Stimdust. Combining AI and neuroscience technologies, the aim of this project is to monitor the structure and function of neurons using millions of micro wireless detectors, with the aim of providing precise neural codes for particular activities -from walking to language processing. Similarly, The Brain Research through Advancing Innovative Neurotechnologies -BRAIN 2025 aims to develop more precise interventional tools to change neural circuit dynamics to enhance function and treat disorders.

Despite its invasiveness, Deep Brain Stimulation (DBS) is currently widely used as a therapeutic treatment for memory skills (Suthana \& Fried, for a review). Most DBS-induced memory enhancement studies show that direct manipulation of the medial temporal lobe (MTL) and wider brain regions (hypothalamus, anterior nucleus of the thalamus) offers a unique opportunity to influence learning and memory performance (Clark et al., 1999; Fell et al., 2012; Lacruz et al., 2010; Suthana et al., 2012). Although the majority of these studies have been carried out with epilepsy and Alzheimer patients who need invasive implantations, further discussions focus on recent developments promoting the efficacy of DBS use for memory enhancement in healthy individuals and the generalizability of these effects over a wide range of working memory tasks (See Suthana \& Fried, 2014).

Research is pointing towards the potential of replacing machines with another brain. Utilising the brain-to-brain interfacing (BTBI) technologies, Vieira et al. (2013) reported a successful real-time transfer of sensorimotor information from the brain of one rat to another. In this BTBI, the encoder rat performed a sensorimotor task, and its cortical activity was transmitted to matching cortical areas of the decoder rat using intracortical microstimulation enabling artificial sensory feedback signals. Furthermore, initiating the first interspecies brain interfacing study, Yoo et al. (2013) trialled a non-invasive EEG-based BTBI to transfer information from a human brain to a rodent, whereby the human brain signals excited the anesthetized rodent's motor brain area. Yoo et al. proposed that these kinds of transfers might offer unexplored opportunities for information flow between individuals and species. The interspecies BTBI can be used in the reverse direction e.g., the transmission of information from non-human species to humans. Moreover, using the internet protocol, bidirectional communications can be possible even if individuals are separated by a great distance, potentially promising another new method of knowledge acquisition.

More extreme efforts have been targeted at developing innovative abilities to cope with the post-industrial information explosion, with a tendency for technology to replicate neurological processes, enabling knowledge seekers to learn new skills in a short time with less effort. Despite being highly controversial, research focus is on brain implants enabling the use of tools for various tasks, including for instance surfing the web -enabling access to intense information from the internet-like systems via chips implanted in the brain. A significant amount of funding has been spent on the advent of this technology, which is primarily concerned with the use of external sensors for communication purposes like sending and receiving information. The neural lace is a research program which intends to combine neuroscience and AI knowledge to create a digital hardware that can be injected into the jugular and travel along to the cortex through the bloodstream (see Musk, 2019). Neurolink, as a company, invests in this and similar projects targeting the creation of such devices that can read brain activity and intervene in neural processes. Another project, the Neurodust, has also focussed on scattering tiny electrodes through the nervous system to record signals (Michael \& Michael, 2007; Seo et al., 2016). The new direction in this strand tends to take steps forward with a global target of developing new technologies to map and control nerve activities. In this area of research, understanding the ways in which the brain learns and stores skills remains highly crucial.

Apparently, neurointervention technologies have been paving the 
way for future directions at a stunning pace (Santhanam et al., 2006). The current paradigm shift in education is also being accelerated through technological innovations and global digital communication, laying the foundations for a new economic perspective that questions the number of years spent in school systems (see e.g., OECD, 2020). One of the targets of this shift is to provide individuals with the most effective tools available and harness their full potential for an uncertain future. In redefining the notion of productivity as centered on individualised education and individuals' fulfilment, these developments present a clear departure from the universal tripartite vertical school systems and their job-focused perspectives. Enhancing cognitive capabilities is still the focus, but not in the same way that was previously achieved -via repetition or mere behavioural exercises. Contemporary methods have instead gravitated towards the transformation of educational processes by adding a new functionality to human capabilities: coupling humans with advent machines or with laboratory products. Such integration, in turn, will necessitate a continuous dialog between teachers, engineers, and scientists from diverse disciplines. Rather than being constrained by disciplinary boundaries, this new attitude unifies insights from multiple fields into the phenomena that drive cognitive function, particularly learning.

Some schools of thought hold that in postmodern societies individuals are expected to learn and execute their work at a much faster speed as a consequence of technology and information exposure (Bourdieu, 1993). Modes of learning and communication are supported by enhanced machines and AI, better equipping learners to improve their ability to deal with fast-paced changes, and adjust to a new era in which economic productivity is measured by abstract terms, such as time expended and information processing speed, rather than by natural/observable results, like iron or coals as centered in the industrial era. The utilisation of these abstract properties is valued highly by the new economic and industrial order, with less tolerance for extended school years in order to gain simple skills for an upscaled workforce (OECD, 2000b).

Such developments draw attention to the possibility of one further scenario, pointing to a paradigm shift in human-machine/laboratory relations:

- Coupling humans with advanced machine/laboratory products: there has been extensive discussion on the complexity of the brain and around the general implications of commercial enhancement technologies in both healthcare and non-healthcare contexts (Scherer, 2005). Beyond restoring lost or absent cognitive/physical functions, there are candidate laboratory-based applications for healthy individuals that can frame education and learning. As research shows, despite the inaccurate risk-benefit assessments, demands for laboratory-based stimulants are increasing among healthy individuals and more individuals have been considering full enhancement of their biological capacities to adapt successfully to the new global order (e.g., see The British Academy, 2012). Those learners seem to 'want' to be equipped with advanced technologies to upscale their abilities, rather than participate in the world on their own. The premise of neuroenhancement technologies for learning could incentivize individuals to decide to move from a mentality of 'need' to 'want' in terms of using these technologies, even if they do not necessarily require them.

It goes without saying that the implications of these advancements have the potential to create remarkable ethical issues. In a society where some members have access to advanced tools and technologies that can potentially alter brain function and thus control cognitive capacities, moral and legal responsibilities are expected to grow exponentially. Neuroethics provides an interdisciplinary platform for debates focusing on the societal, ethical, and legal implications raised in the course of designing and execution of neuroscience research (e.g., Gazzaniga, 2007; Illes \& Sahakian, 2011, particularly the chapters on cognitive enhancement, fairness, and neuroethics; Murphy et al., 2008; Ray, 2016; Yuste et al., 2017). Educational neuroethics is an emerging strand of thought concerned with the ethical issues (i) encountered during educational neuroscience research; and (ii) guiding the ways in which the research and implementations impact on children and society at large (see Knowland, 2020). Further ethical debates are needed to deepen our conception of the behavioural and cognitive consequences of neurointervention e.g., what can neuroscience research offer learners, particularly disadvantaged children? Will these technologies create deep socioeconomic and cultural impacts, through influencing students' performance, exams, and tests via which individuals are promoted through upper classes?

\section{In lieu of conclusion}

As research shows, understanding human educability and learning is like solving a puzzle, the pieces of which are embedded in different fields. Neuroscience has been filling a major knowledge gap by construing the specific neural mechanisms of learning and development that cause individuals to differ in their cognitive functions. In the past, successful engagements between education and various other fields have advanced the understanding of the philosophical, socioeconomic, and anthropological aspects of education, and thus enabled educationalists to (re)evaluate the fundamental questions, such as what we teach, why we teach, how, and what is learnt. Current developments in neuroscience and its accompanying technologies have the potential to revolutionise the 'what's and 'how's, with new avenues exploring the biochemical dimension of educational effort.

The potentials of applied research for education are extensive, but not from a narrow window stipulating a one-way influence of e.g., neuroscience evidence on classroom practices. Instead, the nature of the knowledge in these fields can be analysed by virtue of the epistemic norms theorising the evolutionary characteristics of knowledge, as education plays a major role in the transfer and maintenance of knowledge; and in turn AI and neuroscience research brings its technology back to educational practices. It is this epistemic reciprocity that is important; although the two fields are bounded by their unique targets and methodologies, accumulated knowledge in both fields has already transgressed their respective boundaries.

Despite the theoretical and practical differences between these fields, research has already fuelled new discussions, adding another scenario to the future prospects that may potentially configure education. Polarised views may sometimes deliver controversial messages but are necessary to foresee potential countervailing acts. There is a possibility that the outlined scenarios may not emerge in a pure form, as educational processes are tangled up with unpredictable socioeconomic, technological, and other environmental effects. Instead, certain aspects of one/some of the scenarios could apply more specifically.

On the junction of education, AI, and neuroscience there has been a clear interest in developing a dedicated technology to intervene in the human nervous system, either to reduce the effect of disabilities or significantly enhance skills. Recent trends show that in the future:

- The brain mechanisms producing intelligent behaviour will be of interest. In turn, it is crucial to see the brain as a nonlinear framework, dynamically responding to environmental demands; without this understanding of the degree of its change in response to experience, improvements in educational effort may be impeded.

- In response, educationalists will need to know more about the brain, its development, the cognitive structures involved in learning and behaviour, skill development, intervention strategies, and adaptation processes.

- The major questions, such as to what extent the brain is educable, its structure, the limits of experience-dependent plasticity, and knowledge encoding strategies, are all of great interest in the era ahead, with the premise that the information explosion can be overcome by 
more capable learners/reasoners in this complex new century, possibly with better enhancement technologies.

- Generative (e.g., AI that can generate personalized feedback to learners) and integrative AI (e.g., simulations, virtual reality) have already been applied to various educational implementations to optimize learning. Beyond this, recent AI technologies are engineered from living biology and coupled to it (e.g., BICs). As evidenced by several projects, AI-enhanced brain research is capable to build better models and tools that can simulate and modulate brain activity associated to learning and reasoning.

- Revolutionising the function of the school, the time spent in extended formal schooling will be under more intense scrutiny, with proposals suggesting the shortening of school years and the lowering of the starting age.

- We will also witness the decommodification of knowledge/skill, where it will come to be defined not just by what it is or how people possess qualifications as a function of their schooling, but by what people can do with the kinds of knowledge/skill and their enhancers in the real world. This evolution will lead us into a new area, where traditional learning and ethical approaches have limited applicability.

\section{Acknowledgement}

This work was funded by an award from the UK Economic and Social Research Council. I would like to thank Professor Andrew Tolmie for his feedback on the earlier version of this manuscript.

\section{References}

Amalric, M., \& Dehaene, S. (2018). Cortical circuits for mathematical knowledge: Evidence for a major subdivision within the brain's semantic networks. Philosophical Transactions of the Royal Society B, 373, 20160515.

Ansari, D. (2008). Effects of development and enculturation on number representation in the brain. Nature Reviews Neuroscience, 9, 278-291.

Ansari, D., König, J., Least, M., \& Tokuhama-Espinosa, T. (2017). Developmental cognitive neuroscience: Implications for teachers' pedagogical knowledge. In S. Guerriero (Ed.), Pedagogical knowledge and the changing nature of the teaching profession (pp. 195-222). OECD Publishing.

Aytac, K. (1971). Die schulreformen und die demokratisierung des schulafbaus in England, Schweden, Frankreichund Bundesrepublik Deutschland (Vol. 7, pp. 173-245). Ankara University Academic Archive.

Barco, A., Pittenger, C., \& Kandel, E. R. (2003). CREB, memory enhancement and the treatment of memory disorders: Promises, pitfalls and prospects. Expert Opinion on Therapeutic Targets, 7(1), 101-114.

Bartrés-Faz, D., \& Vidal-Piñeiro, D. (2016). Noninvasive brain stimulation for the study of memory enhancement in aging. European Psychologist, 21(1), 41-54.

Beauchamp, C., \& Beauchamp, M. H. (2013). Boundary as bridge: An analysis of the educational neuroscience literature from a boundary perspective. Educational Psychology Review, 25(1), 47-67.

Bell, D., \& Darlington, H. M. (2020). Educational neuroscience: So what does it mean in the classroom? In M. S. C. Thomas, D. Mareschal, \& I. Dumontheil (Eds.), Educational neuroscience: Development across the life span (pp. 500-525). London: Routledge.

Bishop, D. V. M. (2014). What is educational neuroscience?. Retrieved from https ://figshare.com/articles/What_is_educational_neuroscience_/1030405. (Accessed 21 January 2020).

Blakemore, S. J., \& Frith, U. (2005). The learning brain: Lessons for education. UK: Blackwell.

Bostrom, N., \& Sandberg, A. (2009). Cognitive enhancement: Methods, ethics, regulatory challenges. Science and Engineering Ethics, 15, 311-341.

Bourdieu, P. (1993). Sociology in question. London: Sage.

Bourdiou, P., \& Passeron, J. (1970/1990). Reproduction in education, society and culture. UK: Sage.

Bowers, J. (2016). The practical and principled problems with educational neuroscience. Psychological Review, 123(5), 600-612.

Bruer, J. T. (1997). Education and the brain: A bridge too far. Educational Researcher, 26 (8), 1-13.

Bruer, J. T. (2013). Afterword. In D. Mareschal, B. Butterworth, \& A. Tolmie (Eds.), Educational neuroscience (pp. 349-363). UK: Wiley Blackwell.

Cappelletti, M., Gessaroli, E., Hithersay, R., Mitolo, M., Didino, D., Kanai, R., Cohen Kadosh, R., \& Walsh, V. (2013). Transfer of cognitive training across magnitude dimensions achieved with concurrent brain stimulation of the parietal lobe. Journal of Neuroscience: The Official Journal of the Society for Neuroscience, 33(37), 14899-14907.

Chen, X., Chen, J., Cheng, G., \& Gong, T. (2020). Topics and trends in artificial intelligence assisted human brain research. PloS One, 15(4), Article e0231192.
Clark, V. P., Coffman, B. A., Mayer, A. R., Weisend, M. P., Lane, T. D., Calhoun, V., \& Wassermann, E. M. (2012). TDCS guided using fMRI significantly accelerates learning to identify concealed objects. NeuroImage, 59(1), 117-128.

Clark, K. B., Naritoku, D. K., Smith, D. C., Browning, R. A., \& Jensen, R. A. (1999). Enhanced recognition memory following vagus nerve stimulation in human subjects. Nature Neuroscience, 2(1), 94-98.

Clark, V. P., \& Parasuraman, R. (2014). Neuroenhancement: Enhancing brain and mind in health and in disease. NeuroImage, 85(3), 889-894.

Coffman, B. A., Clark, V. P., \& Parasuraman, R. (2014). Battery powered thought: Enhancement of attention, learning, and memory in healthy adults using transcranial direct current stimulation. NeuroImage, 85, 895-908.

DARPA. (2016a). Boosting synaptic plasticity to accelerate learning. Retrieved from https //www.darpa.mil/news-events/2016-03-16. (Accessed 23 December 2019).

DARPA. (2016b). Implantable 'neural dust' enables precise wireless recording of nerve activity. Retrieved from https://www.darpa.mil/news-events/2016-08-03. (Accessed 23 December 2019).

Davis, A. (2004). The credentials of brain-based learning. Journal of Philosophy of Education, 38(1), 21-36.

Dehaene, S., Piazza, M., Pinel, P., \& Cohen, L. (2003). Three parietal circuits for number processing. Cognitive Neuropsychology, 20, 487-506.

Demeter, E., Mirdamadi, J. L., Meehan, S. K., \& Taylor, S. F. (2016). Short theta burst stimulation to left frontal cortex prior to encoding enhances subsequent recognition memory. Cognitive, Affective, \& Behavioral Neuroscience, 16(4), 724-735.

Derrida, J. (1992). Force of law: The meta-physical foundation of authority. In D. Cornell, M. Rosenfeld, \& D. G. Carlson (Eds.), Deconstruction and the possibility of justice. London: Routledge.

Dewey, J. (1916). Democracy and education. New York: Macmillan.

Dick, F., Lloyd-Fox, S., Blasi, A., Elwell, C., \& Mills, D. (2013). Neuroimaging methods. In D. Mareschal, B. Butterworth, \& A. Tolmie (Eds.), Educational neuroscience (pp. 13-45). UK: Wiley Blackwell.

Dietz, P., Soyka, M., \& Franke, A. G. (2016). Pharmacological neuroenhancement in the field of economics - poll results from an online survey. Frontiers in Psychology, 7, 520.

Donogue, J. (2002). Connecting cortex to machines: Recent advances in brain interfaces. Nature Neuroscience, 5, 1085-1088.

Dubinsky, J. M., Guzey, S. S., Schwartz, M. S., et al. (2019). Contributions of neuroscience knowledge to teachers and their practice. The Neuroscientist, 25(5), 394-407.

Dumontheil, I., \& Mareschal, D. (2020). An introduction to brain and cognitive development: The key concepts you need to know. In M. S. C. Thomas, D. Mareschal, \& I. Dumontheil (Eds.), Educational neuroscience: Development across the life span (pp. 23-49). London: Routledge.

Emerson, R. W., \& Cantlon, J. F. (2012). Early math achievement and functional connectivity in the fronto-parietal network. Developmental Cognitive Neuroscience, 2 (SUPPL. 1), 139-151.

Farah, M. J., Illes, J., Cook-Deegan, R., et al. (2004). Neurocognitive enhancement: What can we do and what should we do? Nature Reviews Neuroscience, 5(5), 421-425.

Fell, J., Staresina, B. P., Do Lam, A. T., Widman, G., Helmstaedter, C., Elger, C. E., \& Axmacher, N. (2012). Memory modulation by weak synchronous deep brain stimulation: A pilot study. Brain Stimulation, 6(3), 270-273.

Fischer, K. W., Goswami, U., \& Geake, J. (2010). \& the task force on the future of educational neuroscience. The future of educational neuroscience. Mind, Brain, and Education, 4, 68-80.

Flöel, A. (2014). tDCS-enhanced motor and cognitive function in neurological diseases. NeuroImage, 8, 936-949.

Foucault, M. (1982). The subject and power. Critical Inquiry, 8(4), 777-795.

Foucault, M. (1995). Discipline and punish: The birth of the prison. New York: Vintage Books.

Franke, A. G., Bonertz, C., Christmann, M., Huss, M., Fellgiebel, A., Hildt, E., \& Lieb, K. (2011). Non-medical use of prescription stimulants and illicit use of stimulants for cognitive enhancement in pupils and students in Germany. Pharmacopsychiatry, 44 (2), 60-66.

Gazzaniga, M. (2007). My brain made me do it. In W. Glannon (Ed.), Defining right and wrong in brain science: Essential readings in neuroethics (pp. 183-194). New York: Dana Press.

Gee, J. P. (2003). What video games have to teach us about learning and literacy. New York: Palgrave Macmillan.

George, M. S., \& Belmaker, R. H. (2000). Transcranial magnetic stimulation in neuropsychiatry. Washington DC: American Psychiatric Press.

Goff, D. C., Leahy, L., Berman, I., Posever, T., Herz, L., Leon, A. C., \& Lynch, G. (2001). A placebo-controlled pilot study of the ampakine CX516 added to clozapine in schizophrenia. Journal of Clinical Psychopharmacology, 21(5), 484-487.

Goswami, U. (2004). Neuroscience and education. British Journal of Educational Psychology, 74(1), 1-14.

Goswami, U. (2020). Reading acquisition and developmental dyslexia: Educational neuroscience and phonological skills. In M. S. C. Thomas, D. Mareschal, \& I. Dumontheil (Eds.), Educational neuroscience: Development across the life span (pp. 144-168). London: Routledge.

Goswami, U., \& Szücs, D. (2011). Educational neuroscience: Developmental mechanisms towards a conceptual framework. NeuroImage, 57, 651-658.

Grafman, J., \& Wassermann, E. (1998). Transcranial magnetic stimulation can measure and modulate learning and memory. Neuropsychologia, 37, 159-167.

Greely, H., Sahakian, B., Harris, J., Kessler, R. C., Gazzaniga, M., Campbell, P., \& Farah, M. J. (2008). Towards responsible use of cognitive enhancing drugs by the healthy. Nature, 456, 702-705.

Heidegger, M. (1993). Basic writings (trans. D. F. Krell. New York: Harper Collins. 
Heidegger, M., Trans, Wieck, F. D., \& Gray, J. G. (1968). What is called thinking? New York: Harper Row.

Heinrichs, S. C. (2007). Enhancement of learning and memory performance: Modality specific mechanisms of action. In R. P. Kesner, \& J. L. Martinez (Eds.), Neurobiology of learning and memory (pp. 541-574). United Kingdom: Academic Press.

Herrnstein, R. J., \& Murray, C. (1994). The bell curve: Intelligence and class structure in American life. New York: Free Press.

Houdé, O., Rossi, S., Lubin, A., \& Joliot, M. (2010). Mapping numerical processing, reading, and executive functions in the developing brain: An fMRI meta- analysis of 52 studies including 842 children. Developmental Science, 13, 876-885.

Howard-Jones, P. A. (2014). Neuroscience and education: Myths and messages. Nature Reviews Neuroscience, 14(12), 817-824.

Illich, I. (1971). Deschooling society. London: Calder \& Boyars.

Jensen, A. R. (1998). The g-factor: The science of mental ability. Westport, CT: Praeger.

Johnson, M. H., \& de Haan, M. (2015). Developmental cognitive neuroscience. Oxford, UK: Wile-Blackwell.

Jones, G., \& Schneider, W. J. (2006). Intelligence, human capital, and economic growth: A bayesian averaging if classical estimates (base) approach. Journal of Economic Growth, 11, 71-93.

Josselyn, S. A., Shi, C., Carlezon, W. A., Jr., Neve, R. L., Nestler, E. J., \& Davis, M. (2001). Long term memory is facilitated by cAMP response element-binding protein overexpression in the amygdala. Journal of Neuroscience, 21(7), 2404-2412.

Kant, I., \& Trans. A. Churthon. (1900). Kant on education. Boston: D.C. Heath and Co.

Kenway, J., Bullen, E., \& Robb, S. (2004). The knowledge economy: The techno-preneur and the problematic future of the university. Policy Futures in Education, 2(2), 330-349.

Kim, J., Kwon, J. T., Kim, H. S., \& Han, J. H. (2013). CREB and neuronal selection for memory trace. Frontiers in Neural Circuits, 7, 44.

Knowland, V. (2020). Educational neuroscience: Ethical perspectives. In M. S. C. Thomas, D. Mareschal, \& I. Dumontheil (Eds.), Educational neuroscience: Development across the life span (pp. 474-499). London: Routledge.

Kwok, V., Dan, G., Yakpo, K., Matthews, S., Fox, P. T., Li, P., \& Tan, L. H. (2017). A metaanalytic study of the neural systems for auditory processing of lexical tones. Frontiers in Human Neuroscience, 11, 375.

Lacruz, M. E., Valentín, A., Seoane, J. J., Morris, R. G., Selway, R. P., \& Alarcón, G. (2010). Single pulse electrical stimulation of the hippocampus is sufficient to impair human episodic memory. Neuroscience, 170(2), 623-632.

Laffere, A., Dick, F., Holt, L. L., \& Tierney, A. (2021). Attentional modulation of neural entrainment to sound streams in children with and without ADHD. NeuroImage, 224 117396.

Liakoni, E., Schaub, M. P., Maier, L. J., Glauser, G. V., \& Liechti, M. E. (2015). The use of prescription drugs, recreational drugs, and "soft enhancers" for cognitive enhancement among Swiss secondary school students. PloS One, 10(10), Article e0141289.

Loh, C. (2001). Learning tools for knowledge nomads: Using personal digital assistants (PDAs) in web-based learning environments. Educational Technology, 41(6), 5-14.

Looi, C. Y., Lim, J., Sella, F., Lolliot, S., Duta, M., Avramenko, A. A., \& Cohen Kadosh, R. (2017). Transcranial random noise stimulation and cognitive training to improve learning and cognition of the atypically developing brain: A pilot study. Scientific Reports, 7(1), 4633.

Luculano, T., \& Cohen Kadosh, R. (2013). The mental cost of cognitive enhancement. Journal of Neuroscience: The Official Journal of the Society for Neuroscience, 33(10), 4482-4486.

Lynch, G. (2002). Memory enhancement: The search for mechanism-based drugs. Nature Neuroscience, 5, 105-108.

Lynch, G., \& Gall, C. M. (2006). Ampakines and the three-fold path to cognitive enhancement. Trends in Neurosciences, 29, 554-562.

Lyotard, J. F. (1984). The postmodern condition: A report on knowledge. In Trans G. Bennington, \& B. Massumi (Eds.). Minneapolis: University of Minnesota Press.

Lyytinen, P., Eklund, K., \& Lyytinen, H. (2005). Language development and literacy skills in late talking toddlers with and without familial risk for dyslexia. Annals of Dyslexia, 55, 166-192.

Macionis, J. J. (2003). Sociology. New Jersey: Pearson Education International.

Maher, B. (2008). Poll results: Look who's doping. Nature, 452, 674.

Marraccini, M. E., Weyandt, L. L., Rossi, J. S., \& Gudmundsdottir, B. G. (2016). Neurocognitive enhancement or impairment? A systematic meta-analysis of prescription stimulant effects on processing speed, decision-making, planning, and cognitive perseveration. Experimental and Clinical Psychopharmacology, 24(4), 269-284.

Michael, K., \& Michael, M. G. (2007). Homo-electricus and the continued speciation of humans. In M. Quigley (Ed.), The encyclopaedia of information ethics and security (pp. 312-318). USA: IGI Global.

Miniussi, C., Harris, J. A., \& Ruzzoli, M. (2013). Modelling non-invasive brain stimulation in cognitive neuroscience. Neuroscience \& Biobehavioral Reviews, 37(8), 1702-1712.

Moghaddam, Y., Yurko, H., Demirkan, H., Tymann, N., \& Reyes, A. (2019). The future of work: How artificial intelligence can augment human capabilities. USA: Business Expert Press.

Molfese, D. L. (2000). Predicting dyslexia at 8 years of age using neonatal brain response. Brain and Language, 72(3), 238-245.

Montessori, M. (1912/1988). The discovery of the child. Oxford, UK: Clio Press.

Moore, P. (2008). Enhancing me: The hope and the hype of human enhancement. Chichester: John Wiley \& Sons.

Moore, D. R., Burgard, D. A., Larson, R. G., \& Ferm, M. (2014). Psychostimulant use among college students during periods of high and low stress: An interdisciplinary approach utilizing both self-report and unobtrusive chemical sample data. Addictive Behaviors, 39(5), 987-993.

Morein-Zamir, S., \& Sahakian, B. J. (2011). Pharmaceutical cognitive enhancement. In J. Illes, \& B. J. Sahakian (Eds.), Oxford handbook of neuroethics (pp. 229-244). UK: Oxford University Press.

Murphy, E., Illes, J., \& Reiner, P. B. (2008). Neuroethics of neuromarketing. Journal of Consumer Behaviour, 7(4-5), 293-302.

Musk, E. (2019). Neuralink: An integrated brain-machine interface platform with thousands of channels. Journal of Medical Internet Research, 21(10), Article e16194.

Nosworthy, N., Bugden, S., Archibald, L., Evans, B., \& Ansari, A. (2013). A two-minute paper and- pencil test of symbolic and non-symbolic numerical magnitude processing explains variability in primary school children's arithmetic competence. PloS One, 8, Article e67918.

OECD. (1996). The knowledge-based economy. Retrieved from http://www.oecd.org/o fficialdocuments/publicdisplaydocumentpdf/? cote=OCDE/GD\%2896\%29102\&doc Language $=\mathrm{En}$.

OECD. (2000a). Schooling for tomorrow: OECD scenarios. Retrieved from http://www. oecd.org/site/schoolingfortomorrowknowledgebase/futuresthinking/scenarios/389 67594.pdf.

OECD. (2000b). Knowledge management in information societies: Education and skills. Paris: OECD.

OECD. (2001). The wider environment of schooling: Deep trends and driving forces. Retrieved from https://www.oecd.org/site/schoolingfortomorrowknowledgebase/f uturesthinking/trends/internationaltrendsanddrivingforces.htm.

OECD. (2020). Learning compass 2030: The evolution of education. Retrieved from http ://www.oecd.org/education/2030-project/teaching-and-learning/learning/megatre nds/.

Pais-Vieira, M., Lebedev, M., Kunicki, C., Wang, J., \& Nicolelis, M. A. L. (2013). A brainto-brain interface for real-time sharing of sensorimotor information. Scientific Reports, 3, 1319.

Partridge, B. J., Bell, S. K., Lucke, J. C., Yeates, S., \& Hall, W. D. (2011). Smart drugs "as common as coffee": Media hype about neuroenhancement. PloS One, 6(11), Article e28416.

Phelps, J., \& Filippi, R. (2020). The cognitive benefits and disadvantages of bilingualism across the lifespan and implications for education. In M. S. C. Thomas, D. Mareschal, \& I. Dumontheil (Eds.), Educational neuroscience: Development across the life span (pp. 388-414). London: Routledge.

Pickering, S. J., \& Howard-Jones, P. (2007). Educators' views on the role of neuroscience in education: Findings from a study of UK and international perspectives. Mind, Brain, and Education, 1(3), 109-113.

Poldrack, R. A. (2008). The role of fMRI in cognitive neuroscience: Where do we stand? Current Opinion in Neurobiology, 18, 223-227.

Popescu, T., Krause, B., Terhune, D. B., Twose, O., Page, T., Humphreys, G., \& Cohen Kadosh, R. (2016). Transcranial random noise stimulation mitigates increased difficulty in an arithmetic learning task. Neuropsychologia, 81, 255-264.

Ramirez, F. O., \& Boli, J. (1987). The political construction of mass schooling: European origins and worldwide institutionalization. Sociology of Education, 60(1), 2-17.

Ray, K. S. (2016). Not just "study drugs" for the rich: Stimulants as moral tools for creating opportunities for socially disadvantaged students. The American Journal of Bioethics: $A J O B, 16(6), 29-38$.

Reis, J., Robertson, E., Krakauer, J. W., Rothwell, J., Marshall, L., Gerloff, C., Wassermann, E., Pascual-Leone, A., Hummel, F., Celnik, P. A., Classen, J., Floel, A., Ziemann, U., Paulus, W., Siebner, H. R., Born, J., \& Cohen, L. G. (2008). Consensus: "Can tDCS and TMS enhance motor learning and memory formation? Brain stimulation, 1(4), 363-369.

Rindermann, H. (2018). Cognitive capitalism: Human capital and the wellbeing of nations. Cambridge: Cambridge University Press.

Rodriguez, V., \& Fitzpatrick, M. (2014). The teaching brain: An evolutionary trait at the heart of education. New York: The New Press.

Roser, M., \& Ortiz-Ospina, E. (2019). Global rise of education. Retrieved from htt ps://ourworldindata.org/global-rise-of-education.

Rousseau, J. J. (1763/1979). Emile: Or on education. In Trans. A. Bloom (Ed.). USA: Basic Books.

Salvador, R., Radua, J., Canales-Rodríguez, E. J., Solanes, A., Sarró, S., Goikolea, J. M., Valiente, A., Monté, G. C., Natividad, M., Guerrero-Pedraza, A., Moro, N., FernándezCorcuera, P., Amann, B. L., Maristany, T., Vieta, E., McKenna, P. J., \& PomarolClotet, E. (2017). Evaluation of machine learning algorithms and structural features for optimal MRI-based diagnostic prediction in psychosis. PloS One, 12(4), Article e0175683.

Santhanam, G., Ryu, S. I., Yu, B. M., Afshar, A., \& Shenoy, K. V. (2006). A highperformance brain-computer interface. Nature, 442, 195-198.

Schellenberg, G. (2020). Music training, individual differences, and plasticity. In M. S. C. Thomas, D. Mareschal, \& I. Dumontheil (Eds.), Educational neuroscience: Development across the life span (pp. 415-441). London: Routledge.

Scherer, M. J. (2005). Living in the state of stuck: How technology impacts the lives of people with disabilities (4th ed.). Cambridge MA: Brookline Books.

Schwartz, M. (2015). Mind, brain and education: A decade of evolution. Mind, Brain, and Education, 9, 64-71.

Seo, D., Neely, R. M., Shen, K., et al. (2016). Wireless recording in the peripheral nervous system with ultrasonic neural dust. Neuron, 91(3), 529-539.

Silvanto, J., Bona, S., Marelli, M., \& Cattaneo, Z. (2018). On the mechanisms of transcranial magnetic stimulation (TMS): How brain state and baseline performance level determine behavioral effects of TMS. Frontiers in Psychology, 9, 741.

Smedt, B. (2014). Advances in the use of neuroscience methods in research on learning and instruction. Frontline Learning Research, 2(4), 7-14. 
Smedt, B. (2020). Sources of variability in mathematical development. In M. S. C. Thomas, D. Mareschal, \& I. Dumontheil (Eds.), Educational neuroscience: Development across the life span (pp. 169-194). London: Routledge.

Snowball, A., Tachtsidis, I., Popescu, T., Thompson, J., Delazer, M., Zamarian, L., Zhu, T., \& Cohen Kadosh, R. (2013). Long term enhancement of brain function and cognition using cognitive training and brain stimulation. Current Biology, 23(11), 987-992.

Squire, L. R., Berg, D., Bloom, F. E., Du Lac, S., Ghosh, A., \& Spitzer, N. C. (2013). Fundamental neuroscience (4th ed.). Oxford, UK: Academic Press.

Stern, E. (2005). Brain goes to school. Trends in Cognitive Sciences, 9(12), 563-565.

Suthana, N., \& Fried, I. (2014). Deep brain stimulation for enhancement of learning and memory. NeuroImage, 85, 996-1002.

Suthana, N., Haneef, Z., Stern, J., Mukamel, R., Behnke, E., Knowlton, B., \& Fried, I. (2012). Memory enhancement and deep-brain stimulation of the entorhinal area. New England Journal of Medicine, 366(6), 502-510.

Szücs, D., \& Goswami, U. (2007). Educational neuroscience: Defining a new discipline for the study of mental representations. Mind, Brain, and Education, 1(3), Article 144127.

Tambini, A., Nee, D. E., \& D’Esposito, M. (2018). Hippocampal-targeted theta-burst stimulation enhances associative memory formation. Journal of Cognitive Neuroscience, 30(10), 1452-1472.

Terney, D., Chaieb, L., Moliadze, V., Antal, A., \& Paulus, W. (2008). Increasing human brain excitability by transcranial high-frequency random noise stimulation. Journa of Neuroscience: The Official Journal of the Society for Neuroscience, 28(52), 14147-14155.

The Academy of Medical Sciences. (2007). Drugs futures: Public engagement on the future of brain science, addiction and drugs. The Academy of medical sciences. Retrieved from https://acmedsci.ac.uk/file-download/34265-524414fc8746a.pdf.

The Royal Society. (2011). Brain waves module 2: Neuroscience implications for education and lifelong learning. London: The Royal Society.

The Royal Society. (2012). Brain waves module 3: Neuroscience, conflict and security. London: The Royal Society.

Thomas, M. S. C., \& Ansari, D. (2020). Educational neuroscience: Why is neuroscience relevant to education? In M. S. C. Thomas, D. Mareschal, \& I. Dumontheil (Eds.), Educational neuroscience: Development across the life span (pp. 3-22). London: Routledge.
Thomas, M. S. C., Ansari, D., \& Knowland, V. C. P. (2019). Annual research review: Educational neuroscience, progress and prospects. Journal of Child Psychology and Psychiatry, 60(4), 477-492.

Tomasello, M. (1999). The cultural origins of human cognition. Cambridge, MA: Harvard University Press.

Tong, X., \& McBridge, C. (2020). Neuroscience in reading and reading difficulties. In M. S. C. Thomas, D. Mareschal, \& I. Dumontheil (Eds.), Educational neuroscience: Development across the life span (pp. 123-143). London: Routledge.

Turkeltaub, P. E., Gareau, L., Flowers, D. L., Zeffiro, T. A., \& Eden, G. F. (2003). Development of neural mechanisms for reading. Nature Neuroscience, 6(7), 767-773.

Varma, S., McCandliss, B. D., \& Schwartz, D. L. (2008). Scientific and pragmatic challenges for bridging education and neuroscience. Educational Researcher, 37(3), $140-152$.

Walsh, V., \& Pascual-Leone, A. (2003). Transcranial magnetic stimulation: A neurochronometrics of mind. USA: MIT Press.

Ward, J. (2010). The student's guide to cognitive neuroscience. New York: Psychology Press. Webster, F. (2002). Theories of the information society (2nd ed.). London: Routledge. Weiler, M., Stieger, K. C., Long, J. M., \& Rapp, P. R. (2020). Transcranial magnetic stimulation in alzheimer's disease: Are we ready? eNeuro, 7(1). ENEURO.023519.2019.

Willingham, D. T. (2009). Three problems in the marriage of neuroscience and education. Cortex, 45(4), 544-545.

Wollmann, H. (2008). Reformen in kommunalpolitik und -verwaltung: England, Schweden, Frankreich und Deutschland im Vergleich. Wiesbaden: Verlag für Sozialwissenschaften.

Yeh, N., \& Rose, N. S. (2019). How can transcranial magnetic stimulation be used to modulate episodic memory? A systematic review and meta-analysis. Frontiers in Psychology, 10, 993.

Yoo, S. S., Kim, H., Filandrianos, E., Taghados, S. J., \& Park, S. (2013). Non-invasive brain-to-brain interface (BBI): Establishing functional links between two brains. PloS One, 8, Article e60410.

Yuste, R., Goering, S., Arcas, B., Bi, G., Carmena, J. M., Carter, A., Fins, J. J., Friesen, P., Gallant, J., Huggins, J. E., Illes, J., Kellmeyer, P., Klein, E., Marblestone, A., Mitchell, C., Parens, E., Pham, M., Rubel, A., Sadato, N., Sullivan, L. S., \& Wolpaw, J. (2017). Four ethical priorities for neurotechnologies and AI. Nature, 551(7679), $159-163$. 